\title{
The development of complexity, accuracy, and fluency in ESP learners' writing: A dynamic systems theory
}

\author{
Alireza Ahmadi - Hussein Meihami
}

\section{DOI: 10.18355/XL.2017.10.03.05}

\begin{abstract}
There is a paucity of research on the writing complexity, accuracy, and fluency (CAF) of English for specific purposes (ESP) learners. Hence, the purpose of this study was to investigate the development of CAF in the ESP learners' writing quality while they wrote essays requiring their topical knowledge and the ones requiring their general knowledge. The study benefited from a dynamic systems theory to investigate the development trends of four ESP learners' writing quality. During the two months, the essays of the ESP learners were examined through different indicators of complexity, accuracy, and fluency. The results revealed that the complexity index of both topical and general essays written by the ESP learners went through the same trends of development. However, this was not the case for the ESP learners' writing fluency and accuracy. Furthermore, the findings revealed that the ESP learners had higher index of complexity, accuracy, and fluency in topical essays at the beginning of the program and at the end of it when compared with the general essays. Additionally, some variations had been observed among the participants.
\end{abstract}

Key words: topical knowledge, ESP learners, complexity, accuracy, fluency

\section{Introduction}

Second language acquisition (SLA) is not a static process, but a dynamic one. Accordingly, the challenges one may encounter in this process are dynamic; meaning that the practitioners of the field cannot solve the issues through making static decisions. During the recent decades, one of the research ground drawing the attention of SLA researchers (e.g., Lambert \& Kormos, 2014; Larsen-Freeman, 2006; Norris \& Ortega, 2009; Revesz, Ekiert, \& Torgersen, 2014) is how to examine the emergence of these challenges in terms of complexity, accuracy, and fluency (hereafter CAF). In the word of Thelen and Smith (1994), the conduction of such research is due to the desire of the SLA researchers to find the direction of "motor change" and its role in intensifying the complexity of the challenges. The SLA researchers use the assumptions they receive from the linguists and from the "first and early language acquisition research" (Larsen-Freeman, 2006; p. 590) to formulate the theoretical underpinnings of CAF which are Emergentism and dynamic systems theory (Spoelman \& Verspoor, 2010).

As an approach to cognition, emergentism follows the principles which highlight the role of interaction between environment and individuals. To touch the issue in SLA, Ellis (1998) believes that the complexity of language is due to having a massive and a complex environment which the development processes are exposed to. It is a metaphorical trick to use emergentism since the development process of language learning is an ever-lasting one. From that perspective, we may establish a relationship between emergentism approach and usage-based language learning (Spoelman \& Verspoor, 2010) in which the external factors such as the frequency of language development factors are crucial in the complexity of the language learning. Owing to this, Tomasello (2003) posits that the type and the token frequency of language structures specify the language structure emergent. 
The relationships existing among the theories about the complexity of language learnings make it even more complicated. As O'Grady (2008a, 2008b) states because of other factors such as the effects of critical period, individual differences, the instruction context, prior knowledge of first language and early limited knowledge of the second language, aptitude, and motivation involving in the development of L2, language learning is not unlike an easy task. Researchers (e.g. De Bot, Lowie, \& Verspoor, 2007; Thelen \& Smith 1994) believe that Dynamic Systems Theory (DST) has similar view of language learning as Emergentism has in that they both deny the need for pre-existing universal grammar. Knowing that and the fact that DST should not be considered as one particular theory (Van Geert, 2008), we can consider it as a complement for Emergentism approach. The researchers who are interested in DST conduct longitudinal and case studies to "discover individual learning trajectories and the interrelationships of parts within the whole" (Polat \& Kim, 2013; p. 186). That all said, in this study we take a DST perspective toward CAF.

L2 writing skill involves multidimensional interactions among L2 writers and real world authors. Hyland (2013a) believes that L2 learners are supposed to "gain fluency in the convection of writing in English to understand their disciplines, to establish their careers or to successfully navigate their learning" (p. 95). The ESP learners feel more daunting while practicing L2 writing because they need to interact in their discipline-related community of practice. Consequently, they need to try their best to establish a fine-tune stance in L2 writing (Baynham, 2000).

Hyland (2013b, p. 241) asserts that "the ability to construct disciplinary arguments is at the heart of conceptual understanding of a field and this means that students must learn to craft their writing in community-specific ways." Writing is considered as a disciplinary discourse rather than a mere skill (Lillis, 2001). At the time, if we consider writing in an ESP context as a disciplinary phenomenon it is inevitable to think of a number of factors imposing challenges to this context and making writing a complex issue for the students. Among these factors one can mention the effect of topical knowledge (He \& Shi, 2012). Topical knowledge which is defined by Alexander, Schallert, and Hare (1991), as "the interaction between one's prior knowledge and the content of a specific passage" (p. 334) is another reason for complexity of language learning. Topical knowledge may have a great influence in language use (Bachman \& Palmer, 1996).

The growth and development processes are thought to be triggered by systems resources (Spoelman \& Verspoor, 2010). The resources have two characteristics: they are complex and at the same time they are limited. Using an analogy, we can say since our resources are limited our growth and development will be limited. Writing in the realm of ESP can be considered as a context with its own resources. The ESP learners find themselves in different discipline-related courses which establish their resources. These resources have both characteristics of systems resources, meaning that they are complex due to the topical loads and at the same time they are limited to a set of finite components. That said, ESP learners may experience a complex context due to the systems resources they interact.

Using a DST approach to growth and development in the writing quality, through a case study we investigated the development of the complexity, accuracy, and fluency in the writing quality of the Iranian ESP learners while they wrote on the topics requiring their topical knowledge and those requiring their general knowledge. We planned to assess the writing quality of the ESP learners to catch their writing development with regard to the systems resources they had. In the next section of the study, we have summarized the descriptions of CAF measurements we used in this study. 


\section{Complexity, Accuracy, and Fluency Measures}

In the eyes of the SLA researchers (e.g., Housen \& Kuiken, 2009; Norris \& Ortega, 2009) CAF should be inconsistently defined and operationalized in a way to produce validated and consistent results which are replicable across different studies. One important distinction should be made, moreover, between the writing proficiency and the writing quality. While the former involves rating scale to gauge learners ability in writing components such as grammar, organization, and mechanics, the later involves in CAF (Lu, 2011). Consequently, CAF can deliver "a full of language development in L2 writing" (Lu, 2011, p. 38).

The syntactic complexity in most of the L2 research has been addressed through verbal subordination (Lambert \& Kormos, 2014). Depending on the skill that the researchers addressed they have used measures such as T-unit (Hunt, 1970), communication unit (Bardovi-Harlig, 1992), and speech unit (Foster, Tonkyn, \& Wigglesworth, 2000). For measuring the complexity of the L2 writing, Ortega (2003) mentions five indexes: Sentence complexity, coordination, subordination, length of production, and particular structures. In 2009, Norris and Ortega proposed three indexes. These indexes are based on L2 learners' level of proficiency. For example, coordination is an appropriate measure for the beginning levels, subordination for the upper-intermediate levels, and sub-causal for the advanced levels. However, Biber, Gray, and Poopon (2011) criticize the approach to measure L2 writing complexity in which subordination is the forepart of the measurement. They believe that this measurement type is not a vivid discriminator of the complexity in the professional academic writing.

In the research studies focusing on accuracy in SLA the proportion of the error free units are very much important (Lambert \& Kormos, 2014). On the contrary, researchers (e.g., Palloti, 2009) believe that this kind of accuracy measurement has validity problems since it ignores the complexity existing in a piece of discourse. More than that, Thewissen (2013) states that using error free units in measuring accuracy cannot accurately differentiate among students at different levels of proficiency. Others (e.g., Bard, Robertson, \& Sorace, 1996) admit that it is not easy to find an acceptability index based on which one can differentiate error-free and errorprone units.

On the contrary, some researchers (e.g., Ellis \& Barkhuizen, 2005; Wigglesworth \& Storch, 2009) believe that due to the correlation existing between global and local errors one can use error-free T-units of all T-units to measure accuracy of L2 production. On top of this, Wigglesworth and Storch (2009) propose another index of measuring accuracy in which the researchers can measure the accuracy of L2 production based on computing the proportion of error-free clauses to all the clauses.

Fluency is the third index of CAF through which one can track L2 development in general, and L2 writing, in particular. Fluency in writing is the extent to which a piece of writing is native like (Polio, 2001). In another definition proposed by Tarone, Downing, Cohen, Gillette, Murie, Dailey (1993, p. 170) "nativeness, standardness, length, ease of reading, idomaticity" are highlighted. Wigglesworth and Storch (2009) propose three indexes of measuring fluency: 1) average number of words per text, 2) average number of T-unit per text, and 3) average number of clauses per text.

That all said, we can figure out that CAF provides measurements of L2 writing development. Lambert and Kormos (2014) believe that CAF is important theoretically and empirically since decision-making can be achieved by using it.

XLinguae Journal, Volume 10 Issue 3, June 2017, ISSN 1337-8384 
Moreover, Skehan (2009) states that CAF is important since it opens up our insights into the cognitive processes that L2 learners are engaged while learning L2 language in general, and L2 writing, in particular.

\section{CAF research through DST}

Due to the new nature of DST, there are not many studies focusing on CAF through the lens of DST (Polat \& Kim, 2014). The principles of DST were first used by Larsen-Freeman in 2006. She examined the variability of CAF among five Chinese learners. She examined grammatical and lexical complexity through clause per t-unit and type token ratio. Moreover, she investigated the accuracy and fluency ratio of correct t-units to all t-units and words per t-unit, respectively. The results of her study showed that a steady improvement was observed in group data. However, the developmental patterns of the individuals were different from the averaged trajectory. The results also indicated that the individuals had their own specific patterns of development which were different from one another. However, the similarity in the development patterns of the group was obvious.

Verspoor, Lowie, and van Dijk (2008) examined CAF measurements of the academic writing of one advanced English learner. In this longitudinal study lasting about eight years the development of the vocabulary and complexity was investigated. The results of the study showed that the variability of the learner's writing development existed in all aspects. In their concluding remarks, Verspoor et al. (2008, p. 229) stated that "there can be no development without variability, and the amount and type of variability can reveal the actual developmental process."

In a three-year study, Spoelman and Verspoor (2010) investigated the development of Finnish writing of a Dutch learner. In their study, they examined complexity and accuracy through the lens of DST. The results of their study showed variability in the learners' writing development over time. In their study they also found that proficiency level might have effect on the improvement of accuracy and complexity, meaning that when learners become more proficient in L2 their writing accuracy and complexity may improve.

\section{The Rationale of the study}

Through the above lines of enquires, one can come to the understanding that variability in the development of L2 writing exists and is a controversial point to be researched (Larsen Freeman, 2006; Spoelman \& Verspoor, 2010; Verspoor et al., 2008). Moreover, what is not paid attention with regard to CAF measurements is the patterns of development for ESP learners. ESP learners participating in writing courses are required to write about different topics. Some of the topics are general, meaning that they require ESP learners to use their general knowledge to write about the topic. However, some of the topics require ESP learners' topical knowledge to compose their writing. That said, the rationale behind doing this study was to investigate the development patterns in the writing of the ESP learners through the lens of DST. The study was to address the following questions:

1. How do the ESP learners develop the complexity of their writing while they are writing about the topics requiring their general knowledge and the ones requiring topical knowledge?

2. How do the ESP learners develop the accuracy of their writing while they are writing about the topics requiring their general knowledge and the ones requiring topical knowledge?

3. How do the ESP learners develop the fluency of their writing while they are writing about the topics requiring their general knowledge and the ones requiring topical knowledge? 


\section{Methodology}

\subsection{Participants and Setting}

Four students of different majors participated in this study. They had enrolled in a writing course held at Shiraz University, Iran. This program introduced the basic elements of essay writing during ten sessions. Two of the participants were girls with majors in civil engineering and oil production engineering. The other participants were two boys majoring in veterinary and oil production. All the participants were Persian native speakers. Before the start of the program, a Preliminary English Test (PET) was administered to obtain their language proficiency level. The results showed that they were at intermediate level of English language proficiency. It should be stated that proficiency was not a variable which the researchers sought. The administrating of PET test was for the reason of individualizing the materials for the participants. We used pseudo names of Boy \#1, \#2 and Girl \#1, \#2 for our participants.

\subsection{Measuring CAF in this study}

As it was stated earlier, we attempted to measure the writing development of the ESP learners while they wrote on specific and general topics in a ten-session writing program. To do so, we went through the lens of DST. We calculated clause per t-unit and dependent clause percentage to address the complexity measure of the ESP learners during the ten sessions. These types of complexity measures are the ones which were recommended by Norris and Ortega (2009) for measuring the complexity of students' writing who are at intermediate level of L2 proficiency. To calculate the accuracy measures, we used the accuracy indicators proposed by Wigglesworth and Storch (2009). Given that, we calculated error-free t-units and error-free clauses to reach the accuracy of ESP learners' writing. Finally, we measured the fluency of ESP learners' writing by calculating the average number of words per text and t-unit per text.

\subsection{Procedure and Data Collection}

After enrolling in a writing course held at Shiraz University, the participants took part in ten sessions of writing instruction. These instructions were around writing a well-developed one paragraph essay. The class time in each session was full of hands on activity in which the learners were required to practice whatever they had been taught. The instructions included how to produce effective paragraphs; a thorough teaching and practicing of topic sentences, sub-topic sentences, supporting sentences, concluding remarks, etc. Each session, the students were asked to write about two topics. The topics were selected by the teacher. This was the topic requiring the general knowledge of the students. The following is one of the topics given to the students to write about:

The government has announced that it plans to build a new university. Some people think that your community would be a good place to locate the university. Compare the advantages and disadvantages of establishing a new university in your community. Use specific details in your discussion.

In addition to that, in each session one topic requiring the topical knowledge of the students was given to them. It should be stated that since the participants were from different majors, they were given different topics based on their disciplines. The following extracts are some of the topics given to the students:

The role of urban villages in achieving sustainability (Civil engineering)

XLinguae Journal, Volume 10 Issue 3, June 2017, ISSN 1337-8384 
On the role of oil discovery: advantages and disadvantages (Oil production engineering)

The role of Cryptosporidium in animal husbandry (Veterinary)

Students were asked to write about the two topics and sent them to the teacher for correction and provision of feedback via email. Each session the teacher provided the students with the necessary corrective feedback. During the ten sessions, each student wrote 20 essays, 10 essays with topics requiring the students' general knowledge and 10 essays requiring their topical knowledge. These essays provided us with good bunch of data to investigate the development of the ESP learners in both prompts.

The teacher created portfolios for each student; consequently, when the students sent their essays the teacher copied their essays in their portfolios and then sent back the essays with some corrective feedback on them to the students.

Inter-rater Reliability

An undeniable threat to the reliability of assessing writing is the subjectivity on the part of the raters (Dunsmuir et al., 2015). In this study 50\% of the essays written by the participants were rated by two raters. Before starting to rate the essays, the lead researcher and an MA graduate in applied linguistics (as the second rater) practiced CAF measurements. Due to this practice, the agreement index between the two raters was satisfactory, $r=.84$.

\subsection{Results}

\section{Development of Complexity in ESP learners' writing}

The complexity of the ESP learners' writing was measured using different indexes including clause per t-unit and dependent clause percentage. Through Figure 1 we illustrate the development of the ESP learners' writing complexity while they wrote about general and topical essays during ten sessions and as overall. It is worth mentioning that to obtain the overall measure of the complexity we summed the complexity mean of the participants' essays once for their general essays and the other time for their topical essays. In developing Figure 1 we used clause per T-unit. 


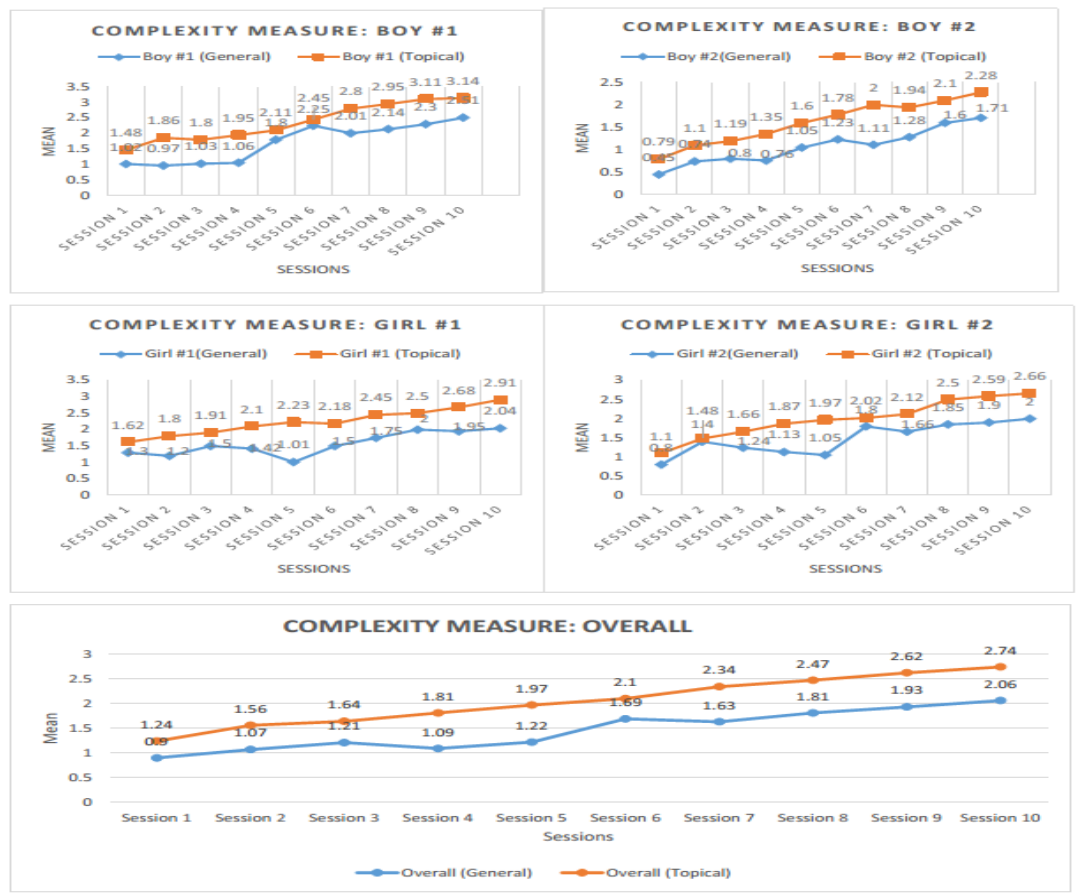

Figure 1: Complexity measure using clause per $\mathrm{T}$-unit

As can be seen in Figure 1 there is a raising trajectory path in the complexity of the ESP learners' writing. Moreover, the overall degree of complexity increased during the ten sessions. Qualitatively speaking, the learners' writing complexity increased while the learners wrote about the topics requiring their topical knowledge and the ones requiring their general knowledge during the ten sessions. However, quantitatively speaking, Figure 1 indicates that when writing about the topics requiring ESP learners' topical knowledge the trajectory of development is less with ups and downs. Moreover, we should note that the ESP learners' writing quality was a little bit higher in the topical essays.

One more complexity measurement we used to obtain the complexity of ESP learners' writing was the dependent clause percentage. Figure 2 shows the results in this regard. 

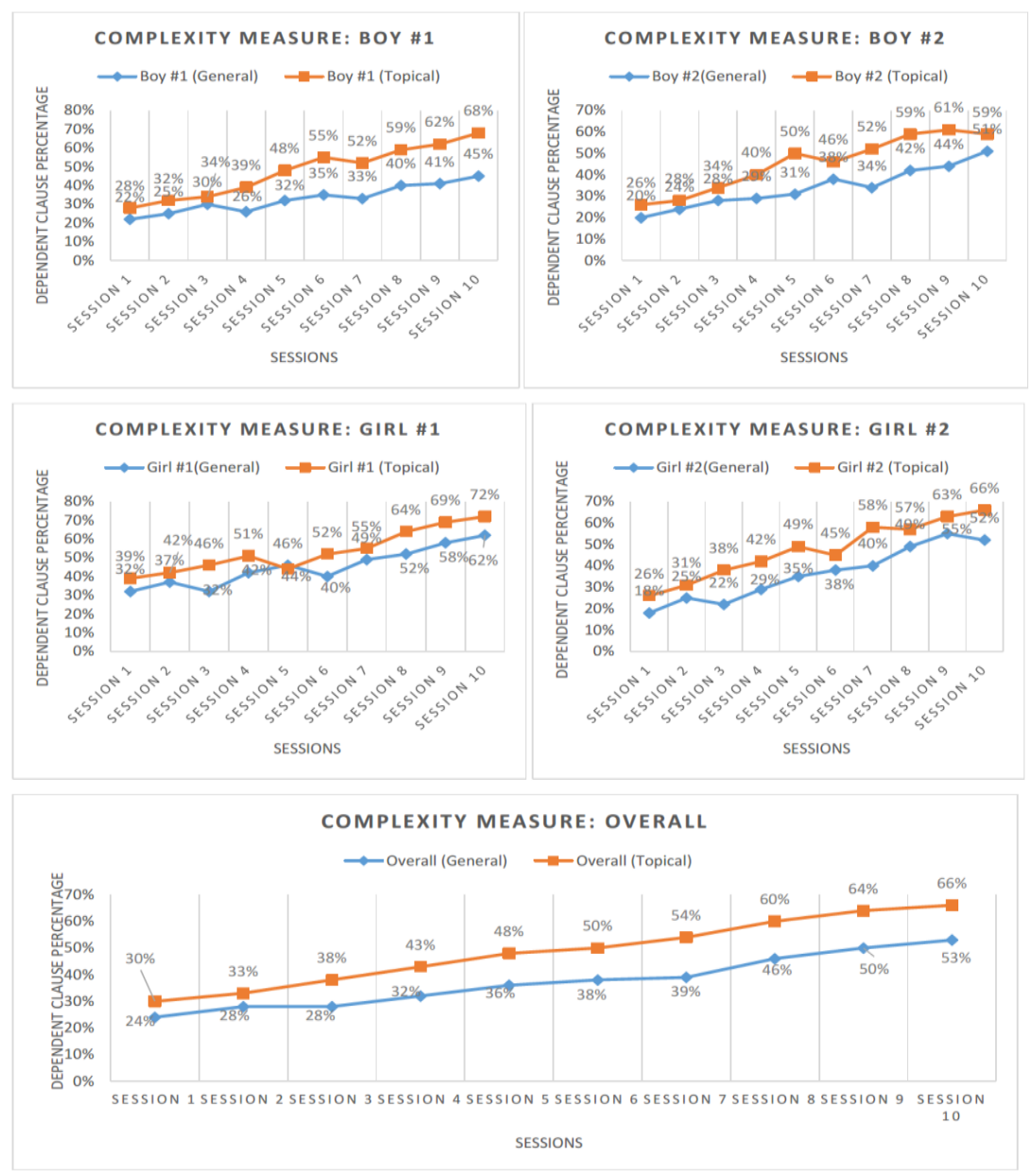

Figure 2: Complexity measure using dependent clause percentage

Figure 2 indicates that the ESP learners' complexity using dependent clause percentage had a raising trajectory path for both essay types: the one requiring topical knowledge and the one requiring general knowledge. Figure 2 is similar to Figure 1 in terms of the participants' writing complexity. In a like manner, Figure 2 shows that quantitatively, ESP learners' writing complexity tended to be higher while they wrote essays requiring topical knowledge.

\section{Development of Accuracy in ESP learners' writing}

The second writing quality index we used to measure the writing quality of the ESP learners was accuracy. To measure writing accuracy we calculated error-free t-units and error-free clauses of the writing productions of ESP learners during the ten sessions. Figure 3 illustrates the results. 

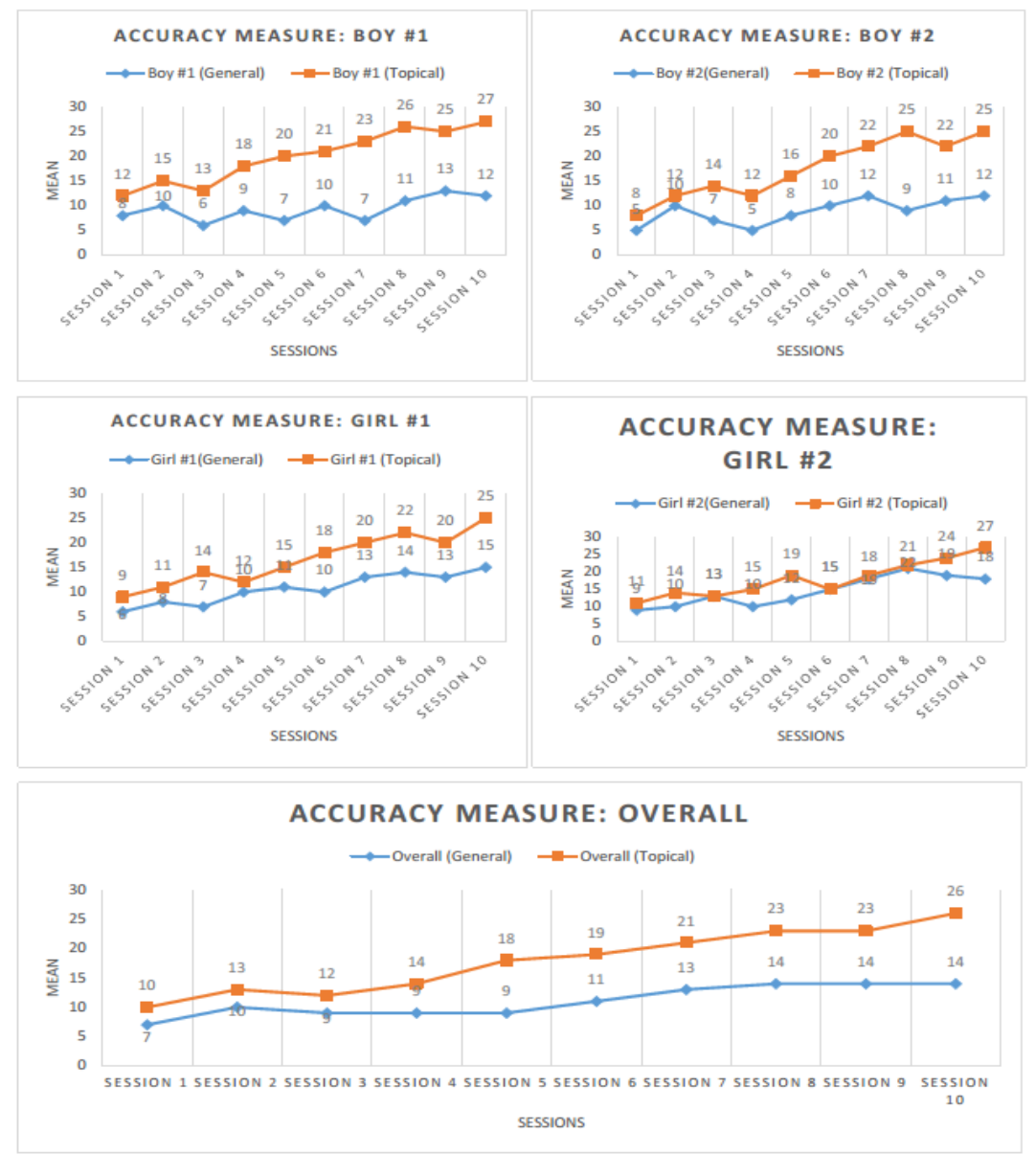

Figure 3: Accuracy measure using error-free T-unit

Figure 3 shows that the accuracy of the ESP learners' writing developed with higher rate when the learners wrote essays which needed their topical knowledge. As depicted, the trajectory path of the ESP learners' writing accuracy is steeper when the learners wrote essays requiring their topical knowledge. Moreover, the overall accuracy mean of the learners' essays shows that the ESP learners' writing accuracy tended to develop more when the learners wrote about the topics requiring topical knowledge. One can also see that in the three last sessions the accuracy for general essays did not show any changes. Figure 3 indicates that there are variations among individuals with regard to the accuracy measure. For instance, as can be seen in Figure 3, Boy \#1 showed a higher accuracy difference trajectory between his writing in topical and general essays while for Girl \#2 the difference is very low. Moreover, the other two participants, Boy \#2 and Girl \#1, we can see that the differences are in average when compared to Boy \#1 and Girl \#2.

One more index we used to measure the accuracy of ESP learners' essays was error-free clauses. Figure 4 indicates the results. 

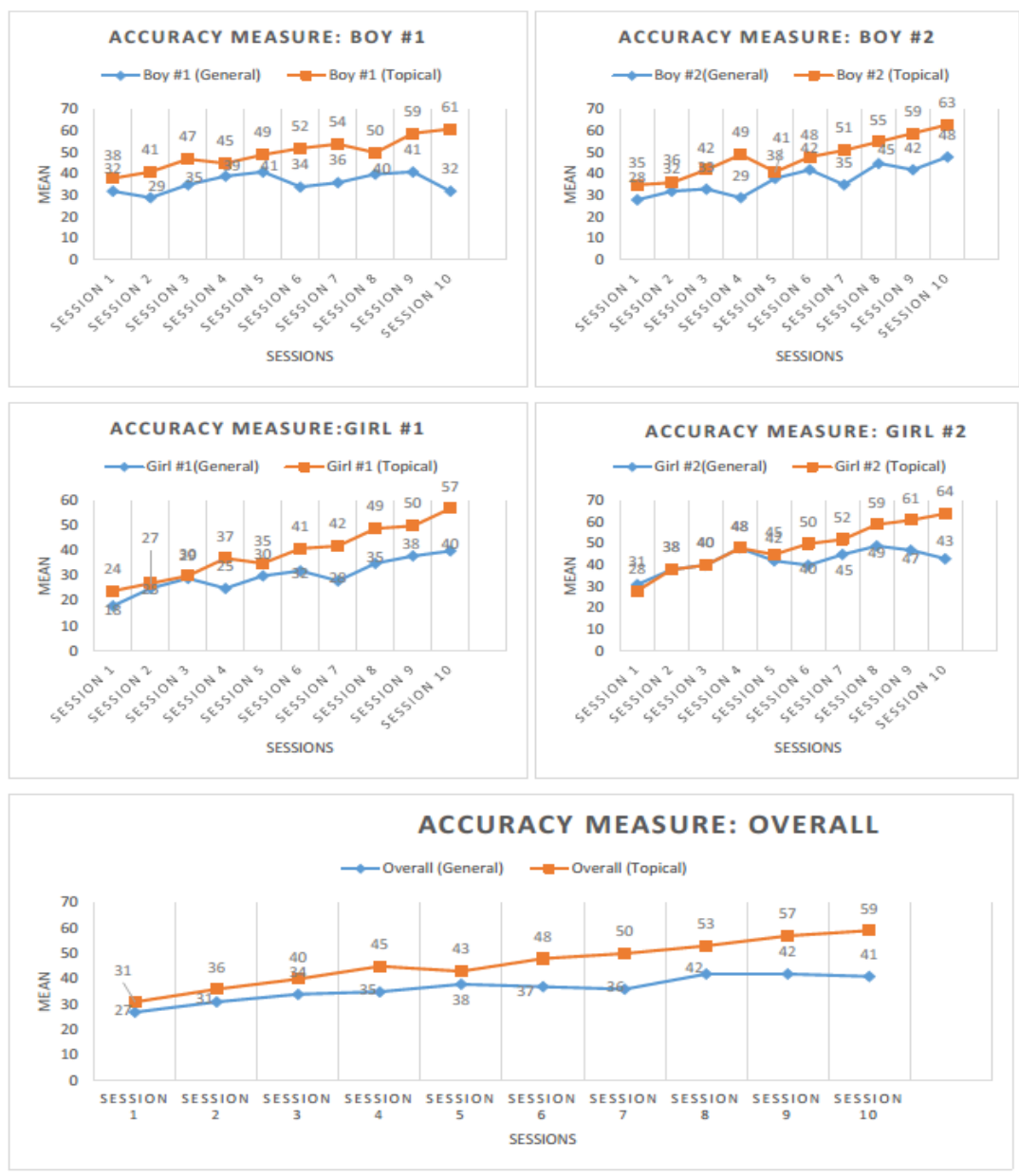

Figure 4: Accuracy measure using error-free clauses

As can be seen from Figure 4, similar to Figure 3, we can understand that the ESP learner's essays tended to be more accurate while they wrote about the topics requiring their topical knowledge. This can be confirmed by refereeing to the steeper trajectory path the mean score of ESP learners' writing accuracy has for topical knowledge essay; comparing to the one we can observe for the general topics. Similar to Figure 3, Figure 4 shows that there are some individual variations among the participants.

\section{Development of Fluency in ESP learners' writing}

To measure the writing fluency of the ESP learners' writings we measured the average number of words per essay and the average number of $t$-units per text. Fig. 5 illustrates the average and the overall number of words per essay during the ten sessions of instruction. 

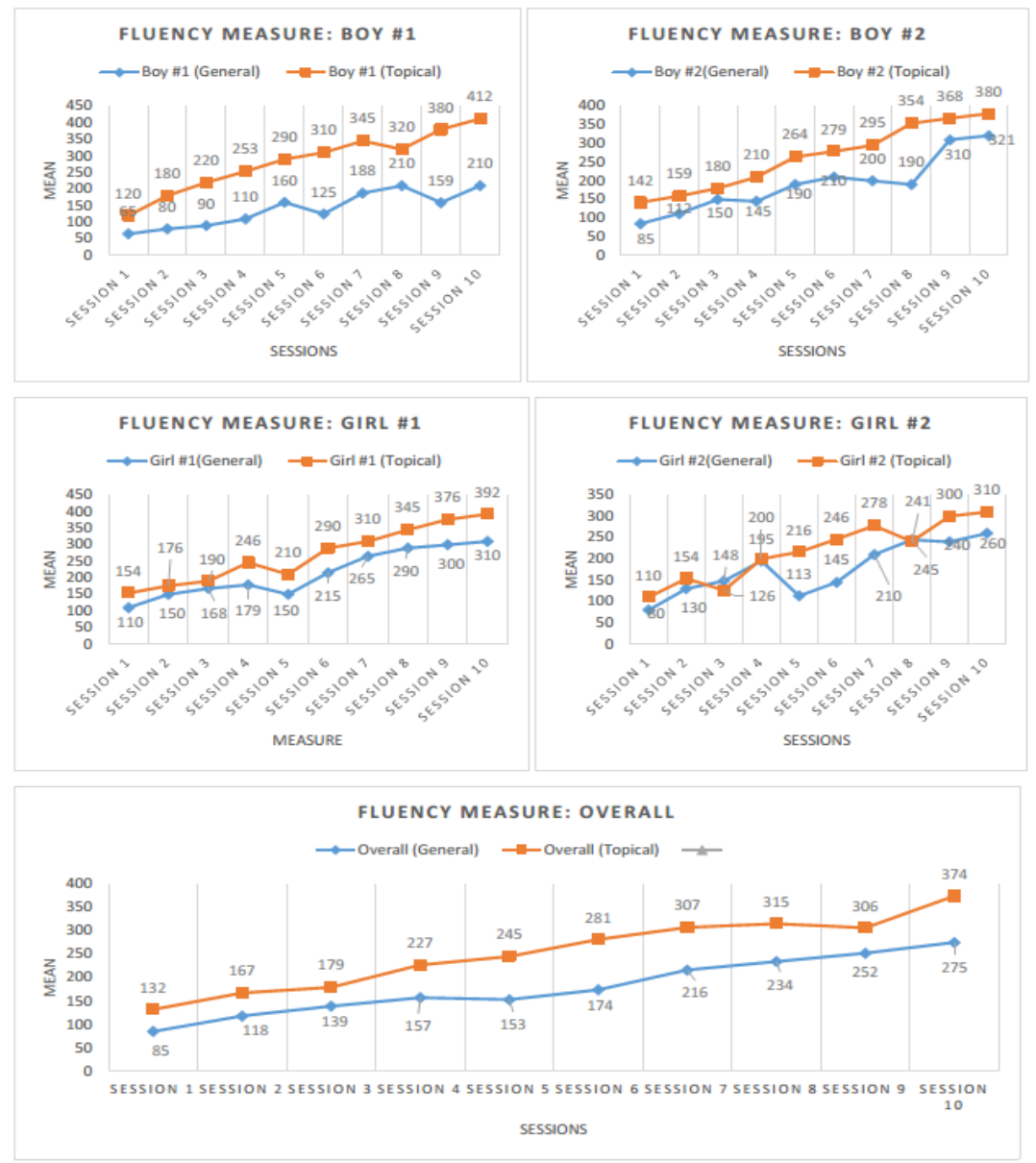

Figure 5: Fluency measure using the average number of words in a text

As can be seen through Figure 5 the development of the ESP learners' writing fluency is steadier while they wrote essays requiring topical knowledge. This is also obvious by analyzing individuals' performance, separately. It can be seen in Figure 5 that there are ups and downs in the fluency of ESP learners when they wrote essays requiring their general knowledge. Moreover, Figure 5 indicates that individual variations can be seen with regard to the fluency of the ESP learners both in their topical and general essays. In this regard, Boy \#2 and Girl \#1 showed less variation in their writing fluency development than Boy \#1 and Girl \#2.

Moreover, we computed average number of t-units as another measure of fluency. Figure 6 indicates the results. 

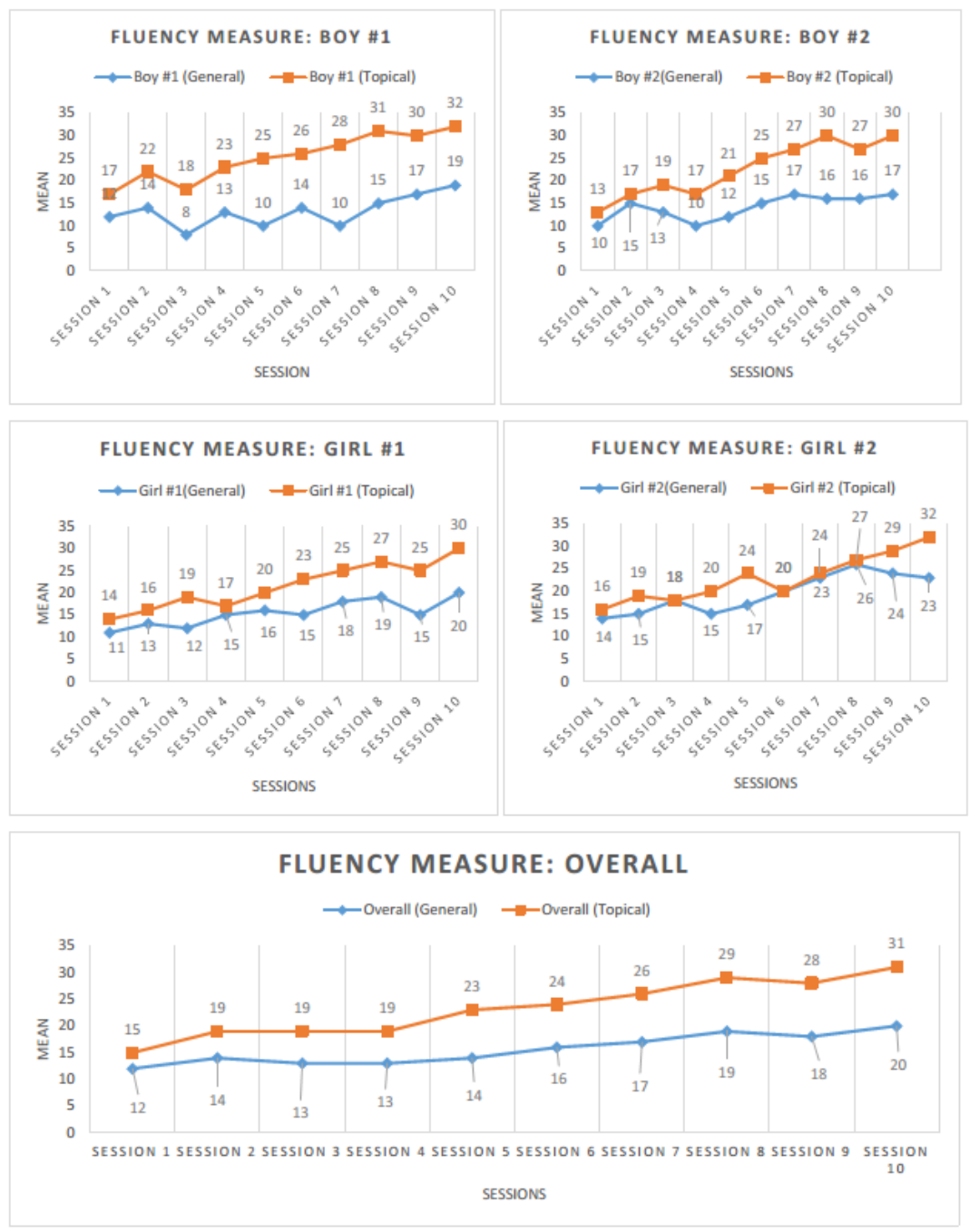

Figure 6: Fluency measure using average number of t-units

Figure 6 shows that the ESP learners are more fluent when they wrote about topics requiring topical knowledge comparing with topics requiring general knowledge. Quantitatively speaking, it can be seen that the mean score of the fluency index is higher in the essays requiring topical knowledge.

\section{Summary of the results}

To obtain the development of the writing quality in the ESP learners' writing performance we used three indexes, namely, complexity (clauses per t-unit and dependent clause percentage), accuracy (error-free t-units and error-free clauses), and fluency (average number of words per essay and average number of t-units per text). Through the course of analysis we came to the understanding that in spite of the existence of some individual differences the complexity index of both topical and general essays written by the ESP learners went through the same trend of 
development; however, ESP learners showed that they wrote topical essays with higher complexity at the start of the program and reached to a higher complexity index at the end of the program when comparing with their general essays.

The same trends of development was observed for the second index of development: the accuracy. However, we observed that ESP learners' general essays illustrated ups and downs. That said, we observed that the accuracy of the ESP learners' topical essays were steadier than the general essays.

Finally, our analyses indicated that the ESP learners went through various ups and downs in developing their writing fluency. Moreover, similar to the other two indexes, ESP learners' topical essays had a higher mean score at the start of instruction and at the end of instruction comparing with the general essays.

\section{Discussion}

In this study we investigated the development of CAF in the ESP learners' writing while they were writing essays requiring their topical knowledge and the ones addressing their general knowledge. The results proved the dynamicity of complexity, accuracy, and fluency in different time intervals (Norris \& Ortega, 2009). The first research question in this study addressed the development of writing complexity of the ESP learners' essays while they wrote about topics requiring their topical knowledge and the ones requiring their general knowledge. The evidence we obtained in this study indicated that ESP learners went through the same trends of development in both topics. However, the complexity of the ESP learners' essays requiring topical knowledge was higher comparing to essays requiring general knowledge (Fig. $1 \& 2$ ).

One way to explain the obtained result about the complexity of the ESP learners' writing can be traced in Schmidt's (1994) noticing hypothesis. Based on this hypothesis the learners' attention toward the learning processes, and various aspects will lead to their awareness with regard to those processes and aspects. The point, however, is that the mere awareness about the process of learning does not lead to learning (Rothman, 2008). The interactions which will be attained from attention to awareness is the main factor leading to learning. We can generalize the argument to the complexity index of the ESP learners' writing. During different moments, the ESP learners read and write about their discipline which exposes them to more complex texts, structures, and writing styles. This can lead to a practice effect, meaning that the more practice with complex structures of their text discipline ESP learners have, the higher their ability will be to produce more complex texts.

The complexification resources can provide another reason for the higher index of complexity in the topical essays of ESP learners. Due to the myriad sources of general knowledge, it is more difficult for the ESP learners to induce it. Given that, ESP learners find it harder to reach awareness in all general resources. Nevertheless, the ESP learners are more focused with regard to the topical knowledge because of the limited nature of topical knowledge. Accordingly, it will be easier for them to produce more complex writing while they are writing about topical essays. Moreover, we can address the results obtained about the complexity to the topical knowledge proficiency. Doubtlessly, we know that the general knowledge proficiency level of ESP learners was lower than that of their topical knowledge proficiency. That said, one can argue that the ESP learners can generate more complex writing productions due to their higher proficiency in topical knowledge.

The second research question addressed the development of ESP learners' writing accuracy in their general and topical essays. The results of the study showed that accuracy showed a dynamic trend, meaning that ESP learners' writing accuracy developed during different time intervals. Although we observed a straightforward development in the accuracy of ESP learners' topical essays, the accuracy

XLinguae Journal, Volume 10 Issue 3, June 2017, ISSN 1337-8384 
development in general essays showed ups and downs. As Spoelman and Verspoor (2010) implied the language proficiency could be a determining factor in the development of writing accuracy. Having that in mind and the fact that the general topics are more varied than the topical ones, one can argue that since the ESP learners participating in this study did not have the same knowledge about general topics their writing accuracy development showed ups and downs.

Some researchers believe that interaction can lead to accuracy (Nassaji \& Tian, 2010; Swain, 1998). In the definition of topical knowledge, Alexander, Schallert, and Hare (1991) stated that topical knowledge is the interaction between prior knowledge and the new content. Bachman and Palmer (1996) emphasized that this interaction is very important for language learners to use language. Consequently, we can argue that the interaction existing between the ESP learners' discipline knowledge and their language use contributes to the higher index of accuracy and more stable development in their writing accuracy when they write essays requiring topical knowledge.

A generalization can be made between the focused and unfocused tasks and the ESP students' writing performances on the general and topical essays. According to Ellis (2004) focused tasks are those tasks which push learners to select some limited sort of choices. On the other hand, unfocused tasks are wider in options. Since focused tasks target at specific features they lead to accuracy improvement of L2 learners. In a like manner, when the ESP learners focus on their discipline they can benefit from specific features. These focused use of the materials within the realm of ESP can lead to their straightforward development in writing accuracy while they write essays requiring their topical knowledge. Nonetheless, the general topics are similar to unfocused task since they are various in subjects and disciplines. This might be a reason why the ESP learners showed a wishy-washy development trend in their general essays accuracy.

The third research question of this study probed the development of fluency in the writing of ESP learners. The evidence we obtained in this study showed that, similar to the accuracy index, the fluency index of the ESP learners had different ups and downs for the general essays while a stable development with fewer ups and downs for the topical essays. That said, we can use automaticity of knowledge which has a direct relationship with writing fluency to explain these findings (Kowal, 2014). Based on the principle of automaticity of knowledge, there is no need for controlling or drawing attention about the process to activate the elements, leading to fluent language productions (Schneider \& Shiffrin, 1977). The topical knowledge that the ESP learners possessed can be considered as procedural knowledge which does not require control or attention. In this regard, the ESP learners can produce more fluent writing while they write essays requiring their topical knowledge in comparison with the essays requiring their general knowledge.

One explanation for the obtained results can be the different purposes for which the ESP learners use a text. According to Dudley-Evens and St John (1998) there are two ways L2 learners could use a text. The first is Text as Linguistic Objective (TALO) in which the L2 learners use the text for grasping the linguistic features. On the other hand, a text can be used as a vehicle of information (TAVI). The main feature of TAVI is that it directs the ESP learners to better understanding of the materials and makes them more fluent in using language. ESP learners, more often than not, involve in their discipline-related materials in a way that they used them for their information (in other words TAVI). Consequently, this can be a reason for which the ESP learners had a higher and more stable fluency index when they wrote essays requiring their topical knowledge in comparison with the time they wrote essays requiring their general knowledge. Overall, the findings indicated that the ESP learners' writing complexity, accuracy, and fluency development is more 
straightforward and stable while the ESP learners write about the topics requiring their topical knowledge.

While we examined the writing quality of the ESP learners through CAF we understood that there were some individual variations among the learners. Figure 1 to 6 indicated that the each learners had his/her own path of development in topical and general essays. We can argue that the individual variations observed among the learners was due to the types of knowledge required for writing an essay. However, care should be taken since other factors such as the instruction context, prior knowledge of first language and early limited knowledge of the second language, aptitude, and motivation are known to cause individual variations (O' Grady, 2008a). Nevertheless, it will be an interesting research query if the researchers focus on the two variables of individual variations in writing quality and their types of essays.

\section{Conclusions and implications}

This study was an attempt to investigate the development of the complexity, accuracy, and fluency of the ESP learners' writing for the topics requiring topical knowledge and the ones requiring general knowledge through a DST approach. The findings of this study indicated that the ESP learners' writing development in terms of complexity, accuracy, and fluency was dynamic, thus supporting the previous studies drawing the conclusion that CAF is dynamic (e.g., Polat \& Kim, 2013; Spoelman \& Verspoor, 2010). It was observed that the ESP learners' writing quality developed through a dynamic trend both in the topical essays and general ones.

The findings also showed that the development in the complexity, accuracy, and fluency of the ESP learners' writing was less with ups and downs and more stable when ESP learners wrote about the topics requiring their topical knowledge in comparison with when they wrote essays requiring their general knowledge. We reasoned that these findings traced us to the features and characteristics we can call for the ESP realm. The noticing hypothesis along with other factors including the purpose of a text for ESP learners, the effect of automaticity of knowledge, and the interaction between the ESP learners' topical knowledge and language use can be the reasons for obtaining these results. These factors seem to help the ESP language learners to produce more complex, more accurate and more fluent writing.

The results of the current study have implication for writing assessment and writing pedagogy in the ESP realm. From an ESP writing assessment perspective, the findings of this study indicated that the ESP learners were able to produce a more complex, more fluent, and more accurate writing samples when writing essays requiring their topical knowledge (He, 2010). This is highly important for the ESP instructors and ESP test developers to specify the purpose for which they assess their ESP students' writing performance. If they want to assess the writing performance of the ESP learners in a domain specific context in relation to their discipline and community of practice, they need to provide the prompts for the learners requiring their topical knowledge; otherwise the ESP learners may not be able to show their ultimate capacity.

The information we obtained with regard to the development of the ESP learners' writing quality in terms of complexity, accuracy, and fluency can have pedagogical implications for writing instruction in the ESP contexts, as well. The ESP instructors can think of the ESP learners' topical knowledge as an opportunity for writing instruction. That said, since the ESP learners showed a higher complexity, accuracy, and fluency in their topical essays in comparison with their general essays, the ESP instructors can instruct more complex materials through the medium of the topical knowledge. Moreover, since the ESP learners often like their disciplines, the ESP instructors can ask them to write for each other on the topics related to their

XLinguae Journal, Volume 10 Issue 3, June 2017, ISSN 1337-8384 
discipline. This helps the ESP learners to feel they write for authentic audiences. Consequently, they can improve their writing ability.

The findings of this study can open up new horizon for further research. Now that we observed the way the ESP learners developed their writing complexity, accuracy, and fluency in topical and general essays, it is interesting to investigate the effect of the mixed topics, the one including both the topical knowledge and the general one, on the writing complexity, accuracy, and fluency of both the ESP and EAP learners. Given that, a further study can be done to investigate how the ESP and EAP learners develop their writing quality using a DST approach. The current study can also be replicated with more number of participants to focus on the quantitative aspects of the ESP learners' writing quality.

\section{Bibliographic references}

ALEXANDER, P. A. - SCHALLERT, D. L. - HARE, V. C. 1991. Coming to Terms: How Researchers in Learning and Literacy Talk About Knowledge. Review of Educational Research, vol. 61, n. 3, pp. 315-343. ISSN: 00346543.

BACHMAN, L. - PALMER, A. 1996. Language testing in practice: Designing and developing useful language tests. Oxford: Oxford University Press. ISBN: 9780194371483.

BARD, E. G. - ROBERTSON, D. - SORACE, A. 1996. Magnitude Estimation of Linguistic Acceptability. Language, vol. 72, n. 1, pp. 32-68. ISSN: 0097-8507.

BARDOVI-HARLIG, K. 1992. A Second Look at T-Unit Analysis: Reconsidering the Sentence. TESOL Quarterly, vol. 26, n. 2, pp. 390-395. ISSN: 1545-7249.

BAYNHAM, M. 2000. Academic Writing in New and Emergent Discipline Areas. In LEA, M. - STIERER, B. (Eds.), Student writing in higher education: New contexts. Buckingham: SRHE and Open University Press. pp. 17-31. ISBN: 978-0335204076.

BIBER, D. - GRAY, B. - POONPON, K. 2011. Should We Use Characteristics of Conversation to Measure Grammatical Complexity in L2 Writing Development? TESOL Quarterly, vol. 45, n. 1, pp. 5-35. ISSN: 1545-7249.

DE BOT, K. - LOWIE, W. - VERSPOOR, M. 2007. A Dynamic Systems Theory Approach to Second Language Acquisition. Bilingualism, Language and Cognition, vol. 10, n. 1, pp. 7-21. ISSN: 1366-7289.

DUDLEY-EVANS, A. - ST. JOHN, M. J. 1998. Developments in English for specific purposes. Cambridge University Press. ISBN: 978-0521596756.

DUNSMUIR, S. - KYRIACOU, M. - BATUWITAGE, S. - HINSON, E. INGRAM, V. - O'SULLIVAN, S. 2015. An Evaluation of the Writing Assessment Measure (WAM) for Children's Narrative Writing. Assessing Writing, vol. 23, n. 1, pp. 1-18. ISSN: 1075-2935.

ELLIS, N. C. 1998. Emergentism, Connectionism and Language Learning. Language learning, vol. 48, n. 4, pp. 631-664.

ELLIS, R. \& BARKHUIZEN, G. 2005. Analyzing learner language. Oxford University Press. ISBN: 978-0194316347

ELLIS, R. 2004.Task-based language learning and teaching. Essex: Oxford University Press. ISBN: 978-0194421591

FOSTER, P. -TONKYN, A. - WIGGLESWORTH, G. 2000. Measuring Spoken Language: A Unit for All Reasons. Applied linguistics, vol. 21, n. 3, pp. 354-375. ISSN 0142-6001.

HE, L., \& SHI, L. 2012. Topical Knowledge and ESL Writing. Language Testing, vol. 29, n. 3, pp. 443-464. ISSN: 0265-5322.

HE, L., 2010. The Effect of Topical Knowledge on L2 Writing. Electronic Theses and Dissertations. Retrieved from: https://open.library.ubc.ca/cIRcle/collections/ubctheses/24/items/1.0071206 
HOUSEN, A. - KUIKEN, F. 2009. Complexity, Accuracy, and Fluency in Second Language Acquisition. Applied Linguistics, vol. 30, n. 4, pp.461-473. ISSN 01426001.

HUNT, K., W. 1970. Do Sentences in the Second Language Grow Like Those in the First? TESOL Quarterly, vol. 4, n. 3, pp. 195-202. ISSN: 1545-7249.

HYLAND, K. 2013a. ESP and Writing. In: PALTRIDGE, B. and STARFIELD, S. (Eds.), Handbook of English for specific purposes. Oxford: Blackwell. pp. 95-114. ISBN: 978-0470655320

HYLAND, K. 2013b. Faculty Feedback: Perceptions and Practices in L2 Disciplinary Writing. Journal of Second Language Writing, vol. 22, n. 3, pp. 240-253. ISSN: 10603743.

KOWAL, I. 2014. Fluency in Second Language Writing: A Developmental Perspective. Studia Linguistica Universitatis Iagellonicae Cracoviensis, vol. 131, pp. 229-246. ISSN 1897-1059.

LAMBERT, C. - KORMOS, J. 2014. Complexity, Accuracy, and Fluency in TaskBased L2 Research: Toward More Developmentally Based Measures of Second Language Acquisition. Applied Linguistics, vol. amu047, pp. 1-9. ISSN 0142-6001.

LARSEN-FREEMAN, D. 2006. The Emergence of Complexity, Fluency, and Accuracy in the Oral and Written Production of Five Chinese Learners of English. Applied Linguistics, vol. 27, n. 4, pp. 590-619. ISSN 0142-6001.

LILLIS, T. M. 2001. Student writing: Access, regulation, desire. New York: Psychology Press. ISBN: 978-0415228022.

LU, X. 2011. A Corpus-Based Evaluation of Syntactic Complexity Measures as Indices of College-Level ESL Writers' Language Development. TESOL Quarterly, vol. 45 , n. 1, pp. 36-62. ISSN: 1545-7249.

NASSAJI, H. - TIAN, J. 2010. Collaborative and Individual Output Tasks and Their Effects on Learning English Phrasal Verbs. Language Teaching Research, vol. 14, n. 4, pp. 397-419. ISSN: 1362-1688

NORRIS, J. M. - ORTEGA, L. 2009. Towards an Organic Approach to Investigating CAF in Instructed SLA: The Case of Complexity. Applied Linguistics, vol. 30, n. 4, pp. 555-578. ISSN 0142-6001.

O'GRADY, W. 2008a. Language without Grammar. In: ROBINSON, P. and ELLIS, N.C. (Eds.), Handbook of cognitive linguistics and second language acquisition, New York: Routledge. pp. 139-67. ISBN: 978-0805853520

O'GRADY, W. 2008b. The Emergentist Program. Lingua, vol. 118, n.4, pp. 447-64. ISSN: 0024-3841.

ORTEGA, L. 2003. Syntactic Complexity Measures and Their Relationship to L2 Proficiency: A Research Synthesis of College-Level L2 Writing. Applied Linguistics, vol. 24, n. 4, pp. 492-518. ISSN 0142-6001.

PALlOTTI, G. 2009. CAF: Defining, Refining and Differentiating Constructs. Applied Linguistics, vol. 30, n. 4, pp. 590-601. ISSN 0142-6001.

POLAT, B. - KIM, Y. 2014. Dynamics of Complexity and Accuracy: A Longitudinal Case Study of Advanced Untutored Development. Applied linguistics, vol. 35, n. 2, pp. 184-207. ISSN 0142-6001.

POLIO, C. 2001. Research Methodology in Second Language Writing Research: The Case of Text Based Studies. In: T. SILVA, \& P. K. MATSUDA (Eds.), On second language writing. Mahwah, NJ: Lawrence Erlbaum, pp. 91-115. ISBN 0-8058-3516-4. REVESZ, A. - EKIERT, M. - TORGERSEN, E. N. 2014. The Effects of Complexity, Accuracy, and Fluency on Communicative Adequacy in Oral Task Performance. Applied Linguistics, vol. 35, n. 5, pp. 1-22. ISSN 0142-6001. 
ROTHMAN, J. 2008. Aspect Selection in Adult L2 Spanish and the Competing Systems Hypothesis: When Pedagogical and Linguistic Rules Conflict. Languages in Contrast, vol. 8, n. 1, pp. 74-106. ISSN 1569-9897.

SCHMIDT, R. 1994. Implicit Learning and the Cognitive Unconscious: Of Artificial Grammars and SLA. In: ELLIS, N. (ed.), Implicit and explicit learning of languages. London: Academic Press, pp. 165-209. ISBN: 0-12-237475-4.

SHIFFRIN, R. M. - SCHNEIDER, W. 1977. Controlled and Automatic Human Information Processing: II. Perceptual Learning, Automatic Attending and a General Theory. Psychological review, vol. 84, n. 2, pp. 127-190. ISSN: 0033-295X.

SKEHAN, P. 2009. Modeling Second Language Performance: Integrating Complexity, Accuracy, Fluency, and Lexis. Applied Linguistics, vol. 30, n. 4, pp. 510-532. ISSN 0142-6001.

SPOELMAN, M. - VERSPOOR, M. 2010. Dynamic Patterns in Development of Accuracy and Complexity: A Longitudinal Case Study in the Acquisition of Finnish. Applied Linguistics, vol. 31, n. 4, pp. 532-553. ISSN 0142-6001.

SWAIN, M. 1998. Focus on Form through Conscious Reflection. In: Doughty, C. \& Williams, J. (Eds.). Focus on form in classroom second language acquisition. Cambridge: Cambridge University Press, pp. 64-81. ISBN: 9780521625517.

TARONE, E. - DOWNING, B. - COHEN, A. - GILlETTE, S. - MURIE, R. DAILEY, B. 1993. The Writing of Southeast Asian-American Students in Secondary School and University. Journal of Second Language Writing, vol. 2, n. 2, pp. 149-172. ISSN: 1060-3743.

THELEN, E. - SMITH, L. B. 1994. A Dynamic systems approach to the development of cognition and action. MIT Press. ISBN: 9780262200950.

THEWISSEN, J. 2013. Capturing L2 Accuracy Developmental Patterns: Insights from an Error-Tagged EFL Learner Corpus. The Modern Language Journal, vol. 97, n. 1, pp. 77-101. ISSN: 1540-4781.

TOMASELLO, M. 2003. Constructing a language: A usage-based theory of language acquisition. Harvard University Press. ISBN 9780674017641.

VERSPOOR, M. - LOWIE, W. - Van DIJK, M. 2008. Variability in Second Language Development from a Dynamic Systems Perspective. The Modern Language Journal, vol. 92, n. 2, pp.214-231. ISSN: 1540-4781.

WIGGLESWORTH, G. - STORCH, N. 2009. Pair versus Individual Writing: Effects on Fluency, Complexity and Accuracy. Language Testing, vol. 26, n. 3, pp. 445-466. ISSN: 0265-5322.

Words: 7120

Characters: 46076 (25,6 standart pages)

Assoc. Prof. Alireza Ahmadi, PhD in TEFL.

Hussein Meihami, PhD Candidate in TEFL.

Department of Foreign Languages and Linguistics

Shiraz University

7194684695, Eram Square, Shiraz

Fars, Iran

arahmadi@shirazu.ac.ir

s.hmeihami@rose.shirazu.ac.ir 